\title{
A gestão democrática rumo ao óbito: o assédio moral em uma escola pública
}

\section{A democratic management en rout for doom:} moral harassment in a public school

La gestión democrática rumbo al óbito: el acoso moral en una escuela pública

RAFAEL PETTA DAUD* Universidade Estadual Paulista, Araraquara- SP, Brasil.

LIDIANE APARECIDA TEIXEIRA* Prefeitura Municipal de Ribeirão Preto, Ribeirão Preto- SP, Brasil.

RESUMO: A partir da problemática "assédio moral nas relações de trabalho", esta investigação, um estudo de caso, objetiva verificar se ela se manifesta no contexto de uma escola pública municipal de educação infantil situada em Ribeirão Preto/SP, assim como analisar seus possíveis efeitos no corpo docente em duas instâncias da ordem do psiquismo: as representações e seus afetos contingentes. Odiagnóstico por nós confirmado destoa dos pressupostos normativos estruturantes da concepção de gestão democrática do ensino, mencionados de modo explícito na legislação brasileira da educação.

Palauras-chave: Assédio moral na escola. Direção escolar e corpo docente. Representações e afetos contingentes.

\begin{abstract}
From the problem of "moral harassment in work relations", this research, a case study, aims to verify if it is manifested in the context of a municipal public pre-school located in the city of Ribeirão Preto / SP, as well as to analyze its possible effects on the faculty in two
\end{abstract}

* Doutorando em Educação Escolar pela Unesp/Araraquara e Mestre em Educação Escolar pela mesma instituição. Especialista em Ética, Valores e Cidadania pela Universidade de São Paulo. Possui Licenciatura Plena em Educação Física pela Universidade Federal de Santa Catarina. E-mail: <rafaelpetta@hotmail.com>.

** Pedagoga, especialista gestão escolar e professora de educação básica I vinculada à Secretaria Municipal de Educação de Ribeirão Preto/SP. E-mail:<li2diane@hotmail.com>. 
instances of the order of psychism: representations and their contingent affections. The diagnosis confirmed by us differs from the structuring normative assumptions of the conception of democratic management of education, mentioned explicitly in the Brazilian education legislation.

Keywords: Harassment at school. School management and faculty. Representations and contingent affects.

RESUMEN: A partir de la problemática "acoso moral en las relaciones de trabajo", esta investigación, un estudio de caso, tiene como objetivo verificar si este se manifiesta en el contexto de una escuela pública municipal de educación infantil situada en Ribeirão Preto/SP, así como analizar sus posibles efectos en el cuerpo docente en dos instancias del orden del psiquismo: las representaciones y sus afectos contingentes. El diagnóstico por nosotros confirmado difiere de los presupuestos normativos estructurantes de la concepción de gestión democrática de la enseñanza, mencionados de modo explícito en la legislación brasileña de la educación.

Palabras clave: Acoso moral en la escuela. Dirección escolar y cuerpo docente. Representaciones y afectos contingentes.

\section{Introdução}

E

ste trabalho se constitui a partir da hipótese de que o assédio moral - uma chaga que incide em diversos contextos laborais desde que o trabalho passou a ser trabalho (COSTA et. al., 2015) - pode se interpor no contexto das instituições educativas não apenas como um inimigo dos postulados que incidem no ideal de gestão democrática (DOURADO, 2001; PARO, 2017), mas também e sobretudo como impeditivo da própria manutenção de um clima escolar favorável à boa convivência entre os corpos docente e discente. Neste sentido, a auto evidência (ARENDT, 2000) implícita na hipótese declarada produz as inquietações que culminam no objetivo desta pesquisa, ou seja, verificar e analisar situações que podem apontar indícios de assédio moral no universo de uma escola púbica municipal que atende a alunos de educação infantil e que se situa em uma região considerada "periférica" da cidade de Ribeirão Preto/SP. Elegemos, portanto, um recorte da totalidade das relações interpessoais que fazem parte do universo da instituição mencionada e direcionamos nosso lócus para a relação estabelecida entre seu principal gestor, que responde pelo cargo denominado por Direção Escolar, e aqueles que, por dever inerente à docência, são imbuídos da tarefa de educar os que são 
os "candidatos à humanidade", conforme expressão arendtiana (ARENDT, 2009). Tratamos, portanto, da relação diretor/professor, em direção descendente.

Neste momento, antes de adentrar de modo específico aos pressupostos metodológicos pertinentes a este trabalho, é necessário lançar luzes às relações que pretendemos estabelecer, a partir das quais nossa categoria de análise poderá ser melhor delimitada.

Portanto, acerca da formulação conceitual de assédio moral assumida para este trabalho, além do conceito em si, privilegiamos sua possível leitura à luz da dimensão psicológica do sujeito que é o seu objeto, projetando os prováveis efeitos, principalmente, à subjetividade. Com isso, partimos da elaboração conceitual proposta por Jeong e Kurcgant (2002), na qual podemos conceber assédio moral como uma forma de violência psicológica - na maioria das vezes velada - cometida por um sujeito investido de poder a partir de uma posição privilegiada do ponto de vista da hierarquia administrativa em uma dada organização contra outro situado de modo descendente com relação às suas determinações, acarretando a este outro consideráveis prejuízos relacionados principalmente ao estresse decorrente do caráter necessariamente repetido, intencional e prolongado das agressões. É a partir deste sentido, enfim, que se insere o segundo movimento, sobre o fenômeno delimitado conforme sua manifestação: no cotidiano em questão, o assédio moral adquire materialidade, por exemplo, através de atos de humilhação, perseguições, exclusão ou intimidação, os quais tendem a gerar angústia no alvo não apenas nos tempos e espaços que são pertinentes ao seu ambiente de trabalho mas, também, nos momentos que lhes são anteriores e posteriores, já que a atividade psíquica humana se caracteriza por sua transcendência com relação ao tempo e espaço (MOSCOVICI, 2003). Afinal, ontologicamente, o homem é ser representante, sendo que a atividade espiritual de sua representação é necessariamente contingenciada pelo amálgama formado pela memória do vivido, pela transitoriedade do vivente e pela projeção de seu vir a ser (ARENDT, 2000). Logo, o objeto representado nem sempre corresponde ao objeto presente, podendo este ser invocado a qualquer momento pela atividade da representação.

Enfim, é na relação de simbiose entre os dois movimentos supracitados que sintetizamos o assédio moral em sua extensão ao psiquismo a partir da seguinte pressuposição: violência psicológica cometida de modo repetido e descendente do ponto de vista do poder institucionalmente estabelecido e que, no psiquismo, transcende a relação espaço-temporal do ato em si.

Depreende-se desta condição o fato de que o assédio moral na escola pode, aos poucos, tanto causar prejuízos relacionados à constituição moral do "assediador" quanto anular simbolicamente os sentidos desejáveis que são atribuídos ao "ser professor" por parte de quem sofre com tal dinâmica de maltrato. Neste interim, é possível inferir os riscos que a prática sistemática de assédio moral por parte de gestores de escolas com relação aos seus professores pode oferecer não apenas aos sujeitos diretamente implicados mas, também, àqueles que estão, ao mesmo tempo, sob a responsabilidade de ambos e que, no 
caso, correspondem aos alunos. Afinal, a priori a responsabilidade sobre a manutenção de uma educação escolar de qualidade oferecida às crianças e adolescentes que frequentam as escolas recai tanto naqueles que são seus gestores quanto naqueles que são os propositores das atividades pedagógicas voltadas à promoção do desenvolvimento humano, tanto intelectual quanto afetivo (PIAGET, 1952), sendo tal responsabilidade atribuída pela própria delimitação de papeis que é inerente à escola e, portando, não aleatória.

Estabelecidas nossas considerações iniciais, a partir das quais o presente estudo tem consolidados os argumentos em prol de sua justificativa, passemos agora para os postulados metodológicos desta investigação.

\section{Metodologia}

Compõem nossa amostra - escolhida de modo intencional sob a manifestação de anuência através do Termo de Consentimento Livre e Esclarecido - oito profissionais de educação infantil do sexo feminino e atuantes no universo de investigação. A média de idade das participantes foi calculada em 42,25 anos, sendo o tempo médio de exercício em docência na educação infantil calculado, com duas casas decimais, em 11,62 anos.

Todas as professoras frequentam a unidade escolar durante o período vespertino, sendo que durante o período matutino trabalham em outras unidades, públicas ou particulares, principalmente como forma de complementar a renda.

O instrumento para esta investigação corresponde a um questionário semiestruturado composto por perguntas abertas e fechadas que visam captar dados da percepção das docentes entrevistadas referentes à presença ou não de assédio moral no universo da unidade escolar, assim como elementos relacionados a possíveis tensões que tal assédio exerce na ordem afetiva das representações das professoras. Portanto, as questões intentam: identificar a presença (ou não) e frequência correlata de situações de intimidação, maltrato, ameaça, humilhação ou demais ofensas proferidas pela diretora da unidade escolar contra as professoras pesquisadas, tanto a partir de experiências próprias quanto através de testemunhos voltados a situações em que elas não estejam envolvidas diretamente, mensurar a presença de sentimentos passivos - como, por exemplo, mágoa, medo, insegurança etc. - e/ou reativos - como revolta, indignação, raiva etc. - como resposta à vivência ou testemunho diante das situações de assédio moral e verificar como o assédio moral influi no apreço que as professoras podem ter com relação à profissão.

Como procedimento para coleta de dados, todas as profissionais foram contatadas previamente e, após manifestarem concordância com a participação na pesquisa, responderam ao instrumento de investigação durante uma reunião de Trabalho Docente Coletivo (TDC), na presença da pesquisadora responsável. Esta, por sinal, formalizou sua disposição para o esclarecimento de eventuais dúvidas por parte das professoras 
respondentes quanto ao preenchimento dos questionários, sendo que a formalização, embora explícita no Termo de Consentimento Livre e Esclarecido, foi reiterada verbalmente.

Como procedimento para a análise dos dados, inicialmente as respostas obtidas foram agrupadas em três categorias: percepção de assédio moral contra si, percepção de assédio moral contra colegas de trabalho - ambas delimitadas conforme a frequência mínima semanal dos eventos de assédio relatados pelas respondentes - e sentimentos resultantes do assédio moral sofrido, sendo que para esta categoria também foram contabilizados os casos em que, conforme relato próprio, houve algum tipo de agressão, porém sem frequência regular. Em seguida, a partir do cruzamento entre as categorias "assédio moral percebido contra si" e "assédio moral percebido contra colegas de trabalho", buscamos identificar se os índices pertinentes a cada uma delas seriam indicativos, do ponto de vista diagnóstico, da presença do fenômeno pesquisado em nosso universo de investigação, situação aparentemente confirmada mediante a constatação de que duas docentes indicaram frequência igual ou maior do que a semanal ao assédio percebido contra si e cinco professoras atribuíram frequência igual ou maior do que a semanal ao assédio percebido contra colegas de trabalho, conforme veremos mais adiante. Aliás, chama-nos a atenção o fato adjacente no qual todas as docentes entrevistadas relataram ter presenciado, ao menos uma vez em um período de seis meses, alguma situação de intimidação, maltrato, ameaça, humilhação ou ofensa por parte da diretora da unidade escolar contra si ou contra alguma colega de trabalho. Este panorama, apesar de, se tomado isoladamente, ser insuficiente para classificar os relatos como assédio moral, reforça a hipótese de que esta forma de violência está longe de ser incomum no contexto da escola em questão.

Por ser reduzida a amostra para a investigação, delimitada metodologicamente como um estudo de caso, não houve necessidade de submissão dos resultados à análise combinatória estatística, visto que o cruzamento entre as variáveis "assédio moral sofrido" e "sentimentos resultantes do assédio" - cujas relações nos interessam para este trabalho - pôde ser analisado, para cada respondente, de modo individual. Deste modo, foi possível visualizar com mais detalhes tais relações para que pudéssemos, posteriormente, melhor vislumbrar o modo com o qual o assédio moral sofrido pode ter agido como mediador dos afetos contingentes ao psiquismo para gerar os sentimentos que foram relatados, de modo espontâneo, pelas professoras respondentes - sem perder de vista o fato de que, pela própria plasticidade que caracteriza a instância das representações, tais sentimentos podem facilmente transcender a relação espaço/temporal que estabelecem com seus fatos geradores, os quais, no caso específico desta investigação, correspondem às experiências vividas com o assédio empreendido pela diretora da unidade escolar.

Passemos, portanto, à explicitação pormenorizada dos resultados que foram obtidos, atrelados às suas respectivas discussões. 


\section{Resultados e discussão}

Como relação à pergunta "vocêjá se sentiu intimidada, maltratada, ameaçada, humilhada ou ofendida nos últimos seis meses por parte de um ou mais representantes da equipe gestora de sua unidade educacional?", todas as docentes responderam de modo afirmativo, embora com distintas frequências, conforme observamos em Tabela 1:

\section{Tabela 1 - Situações que podem indicar a presença de assédio moral, conforme frequência e percepção das docentes pesquisadas com relação às experiências próprias}

\begin{tabular}{l|c}
\hline $\begin{array}{l}\text { Você já se sentiu intimidada, maltratada, ameaçada, humilhada ou } \\
\text { ofendida nos últimos } 6 \text { meses por parte de um ou mais representantes } \\
\text { da equipe gestora de sua unidade educacional? }\end{array}$ & $\begin{array}{c}\text { Docentes } \\
(\mathbf{n}=\mathbf{8})\end{array}$ \\
\hline Não. & 0 \\
\hline Sim. Pelo menos uma vez nos últimos seis meses. & 5 \\
\hline Sim. Pelo menos uma vez por mês. & 1 \\
\hline Sim. Pelo menos uma vez por semana. & 0 \\
\hline Sim. Mais de uma vez por semana. & 1 \\
\hline Sim. Praticamente todos os dias. & 1 \\
\hline
\end{tabular}

Fonte: Autores desta investigação

Sem desconsiderar o fato de que nem sempre é possível mensurar os danos às vítimas das situações descritas em Tabela 1 através da frequência com que as situações ocorrem - pois estaríamos simplificando em demasia a complexidade que caracteriza os sintomas que decorrem da mediação entre um ato de agressão, seu agente e seu receptor, sendo que a proporção entre a frequência do ato e a intensidade do sintoma propriamente dito não é, necessariamente, direta - entendemos ser presumível o fato de que se enquadram na definição de assédio moral por nós assumida os eventos que se repetem, pelo menos, semanalmente, visto que a repetição semanal coaduna com regularidade sobre a qual se qualifica o viés sistemático das agressões (HIRIGOYEN, 2002). Por esta feita, teríamos então duas professoras vitimizadas por esta forma de violência, ao menos conforme a representação que elas têm da relação entre si e o outro que, à luz da hierarquia da instituição em questão, poderíamos denominar por "outro autoridade".

Obviamente, dado o fato de que as respostas obtidas provêm da percepção dos sujeitos respondentes - o que as sujeita aos limites inerentes ao gesto interpretativo -, consideramo-las apenas como indícios a partir dos quais podemos nos aproximar da realidade que pretendemos mensurar. Afinal, necessariamente devemos considerar, além da percepção, algumas instabilidades que se devem à plasticidade da própria 
representação confrontada com o cotidiano representado, dentre as quais (1) a possibilidade de que atitudes a priori de não agressão sejam representadas como agressão e (2) atitudes de agressão sejam representadas como não agressão.

Respeitada a advertência acerca das anuências do gesto representativo, é com base nelas que nos orientamos para ponderar os dados referentes ao assédio moral percebido sob testemunho, ou seja, sem que o sujeito observador esteja implicado diretamente na cena observada, conforme Tabela 2:

\section{Tabela 2 - Situações que podem indicar a presença de assédio moral, conforme frequência e percepção das docentes pesquisadas com relação às experiências testemunhadas}

\begin{tabular}{l|c}
\hline $\begin{array}{l}\text { Você já se presenciou alguma colega ser intimidada, maltratada, } \\
\text { ameaçada, humilhada ou ofendida nos últimos } 6 \text { meses por parte de um } \\
\text { ou mais representantes da equipe gestora de sua Unidade Educacional? }\end{array}$ & $\begin{array}{c}\text { Docentes } \\
(\mathbf{n}=\mathbf{8})\end{array}$ \\
\hline Não. & 0 \\
\hline Sim. Pelo menos uma vez nos últimos 6 meses. & 2 \\
\hline Sim. Pelo menos uma vez por mês. & 1 \\
\hline Sim. Pelo menos uma vez por semana. & 3 \\
\hline Sim. Mais de uma vez por semana. & 2 \\
\hline Sim. Praticamente todos os dias. & 0 \\
\hline
\end{tabular}

Fonte: Autores desta investigação

Pelo menos cinco docentes pesquisadas consideram ter presenciado, semanalmente, uma ou mais situações dentre as supra descritas. Além disso, nenhuma professora respondeu à questão de modo negativo, fato que sugere regularidade quanto a presença de tais situações na conduta de quem responde pela equipe gestora da Unidade Educacional, no caso, a diretora ${ }^{1}$. Em outros termos, aparentemente práticas de intimidação, maltrato, ameaça, humilhação ou ofensas diversas são corriqueiras no modo com o qual a profissional responsável pelo cargo de direção lida com o exercício do poder que lhe é concedido por decorrência de sua posição na hierarquia institucional, fato que tende a se comprovar quando perguntamos às professoras entrevistadas sobre a quantidade de docentes que elas presenciaram sendo vítimas de tais formas de violência. Sobre esta questão, duas professoras assinalaram, em nosso instrumento, a alternativa "de 2 a 5 docentes". Três professoras indicaram ter presenciado "de 6 a 10 docentes" e outras três responderam "mais de 10 docentes" à mesma questão. Ou seja, apesar de nem todas as situações corresponderem, necessariamente, à classificação nos termos de assédio moral conforme a definição por nós assumida nesta investigação, elas são indicadoras de uma lógica de ação que é condição necessária, embora não única, ao seu exercício: sobrepujar, 
pelo exercício arbitrário de poder, quem se situa de modo descendente com relação a si no horizonte da hierarquia institucional, sendo tal arbitrariedade mediada pela ausência de conteúdos morais por parte do agente, dado que elementos como força, poder, intolerância e falta de respeito lhes são mais importantes do que a generosidade, a justiça e o respeito no tratamento com o outro que se encontra sob sua chefia.

Ao assumir esta lógica como orientação de conduta, a diretora da unidade escolar em questão se aproxima de práticas que, de acordo com a Organização Internacional do Trabalho (OIT, 2003), podem afetar seriamente a saúde física e psíquica das professoras que estão sob suas orientações administrativas, submetendo-as, inclusive, ao risco de suicídio (IDEM). Para Oliveira (2013), do ponto de vista sintomático estes danos começam a se revelar em suas vítimas por meio de problemas como:

\begin{abstract}
(...) endurecimento ou esfriamento das relações no ambiente de trabalho; dificuldades de enfrentar as agressões ou interagir em equipe; dificuldades emocionais como irritação constante, falta de confiança em si, cansaço exagerado, diminuição da capacidade para enfrentar o estresse e pensamentos repetitivos; alterações do sono; dificuldade para dormir, pesadelos, interrupções frequentes do sono, insônia; alteração da capacidade de concentrar-se e memorizar (amnésia psicogênica, diminuição da capacidade de recordar os acontecimentos); anulação dos pensamento ou sentimentos que relembrem a tortura psicológica, como forma de se proteger e resistir; diminuição da capacidade de fazer novas amizades; morte social: redução do afeto, sentimento de isolamento ou indiferença com respeito ao sofrimento alheio; tristeza profunda; sensação negativa de futuro; vivência depressiva; mudança de personalidade; prática de violência moral; sentimento de culpa; pensamentos suicidas, tentativas de suicídio; aumento do peso ou emagrecimento exagerado. Distúrbios digestivos; hipertensão arterial; tremores; palpitações; Aumento de bebidas alcoólicas e outras drogas; estresse; falta de equilíbrio quanto às manifestações emocionais, por exemplo, com crises de choro ou de raiva; Pedido de demissão; Tensão nos relacionamentos afetivos (OLIVEIRA, 2013, p. 138).
\end{abstract}

No caso dos depoimentos coletados por ocasião de nossa investigação, é possível perceber, inclusive, que os danos mencionados são capazes de transcender a relação direta entre agressor e vítima e incidir em quem, de fora, constantemente presencia as situações de intimidação, conforme a fala de uma das professoras entrevistadas, aqui denominada por P1: "Já me senti intimidada por assistir outros professores sendo intimidados por vários motivos durante os últimos seis meses. Meu medo era que a qualquer momento fosse acontecer comigo".

Não obstante, sobre os sentimentos infligidos a partir de tais situações, pedimos para que as docentes participantes desta pesquisa indicassem, em nosso instrumento de investigação, até três palavras representativas dos que, nelas, foram mais frequentes com relação às agressões sofridas, sejam elas enquadradas nos termos do assédio moral em sua via de repetição (lembremos do critério por nós adotado neste trabalho, ou seja, considerar como assédio moral as agressões que se repetem, ao menos, semanalmente) ou não. Em seguida, separamos as respectivas respostas sobre este item em três categorias: sentimentos que se 
relacionam com uma postura tendencialmente mais passiva com relação às agressões (tais como medo, ansiedade e insegurança, p.ex.), sentimentos relacionados com uma postura tendencialmente mais ativa com relação às agressões (como indignação, raiva e revolta, p. ex.) e sentimentos que podem se relacionar tanto com uma postura tendencialmente mais passiva quanto mais ativa (como os mediados pela percepção de ter sido ofendida ou desrespeitada, p. ex., cujas atitudes derivadas podem ser tanto de ação quanto de introspecção). Deste modo, dos 24 termos citados (cada uma das oito professoras entrevistada citou três), 16 (67\%) se enquadram na primeira categoria, quatro (16,5\%) na segunda e quatro $(16,5 \%)$ na terceira. Com isso, sentimentos como medo, desânimo ou impotência foram mais prevalentes do que raiva, injustiça ou indignação, por exemplo. Esta prevalência, aliás, provavelmente não se restringe ao instante em que as atitudes de agressão são empreendidas pela diretora da unidade educacional, já que uma das características centrais da estância da representação no psiquismo se dá, como já mencionamos, por sua transcendência temporal relacionada ao representado (ARENDT, 2000; MOSCOVICI, 2003).

Na prática, considerando esta premissa em sua projeção com relação ao objeto da investigação, podemos afirmar que para as professoras as agressões sofridas provavelmente são rememoradas por diversas vezes após o instante em que ocorreram, assim como os sentimentos lhes cindem de modo concomitante. Afinal, dada a conjectura do trabalho escolar, no dia seguinte após terem sofrido uma agressão as professoras, obrigatoriamente, terão que conviver com o sujeito agressor, fato que é impeditivo de que as expectativas mediadas pela angústia de estar diante de seu algoz possam cessar. Em alguns casos, inclusive, esta condição pode afetar os próprios sentidos que elas atribuem ao trabalho que desenvolvem, conforme nos indicam os dados em Tabela 3, referentes às consequências do maltrato para a relação afetiva que estabelecem com a profissão:

\section{Tabela 3 - Relação entre as agressões sofridas e as motivações relacionadas com a profissão docente}

\section{Com relação às consequências das ocasiões retratadas para a sua profissão, assinale a alternativa que mais se aproxima da explicação}

Não geram nenhum efeito.

As situações me incomodam um pouco. Porém, sigo adiante, pois gosto do que faço.

Me abalam consideravelmente. Tenho vontade de desistir de minha profissão.
Docentes

$(n=8)$

Fonte: Autores desta investigação

Percebe-se, portanto, que as agressões que foram relatadas pelas docentes pesquisadas não são inócuas, sendo que, para duas delas, seus efeitos são fortes o suficiente para assumirem o valor de causa à vontade de desistir do exercício da docência, fato cuja 
manutenção a longo prazo pode, sem dúvida, adquirir potencialidade suficiente para acarretar prejuízos à integridade psíquica das profissionais.

Em todo o caso, embora tenhamos captado apenas um pequeno recorte de uma realidade certamente mais complexa, os dados que obtivemos não nos deixam dúvidas quanto à natureza das ações provenientes da profissional responsável pelo cargo de direção com relação às professoras sob sua administração, ou seja, ações demarcadas por aquilo que se pode entender como abuso de poder, abuso este que, ao ser objetivado por meio de intimidações, maltratos, ameaças, humilhações ou demais ofensas, nos termos de seus efeitos coloca as docentes em uma situação, no mínimo, desconfortável no que tange a um ambiente considerado saudável para a própria realização da pedagogia.

Amiúde, correspondendo ou não tais ações ao constructo de assédio moral assumido para este trabalho, elas não deixam de revelar tanto a carência de conteúdos morais (como o respeito, a justiça, a solidariedade etc.) tão caros a qualquer relação interpessoal tida como desejável quanto a impossibilidade de que a ética venha a qualificar a própria gestão escolar diante de um paradigma que, conforme a própria legislação brasileira, necessariamente deve se orientar pelos princípios que são coerentes com a gestão democrática (BRASIL, 1988², 199633). Sobre esta questão, questionamos: como é possível o exercício da gestão democrática em um ambiente demarcado por relações de autocracia, cujo autoritarismo desmedido e imoral se sobrepõe ao tratamento justo?

Tecidas estas observações, e certos de que a resposta à última questão não é de difícil elaboração, dada a obviedade de sua negativa, passamos para nossas considerações finais.

\section{Considerações Finais}

Com este trabalho realizamos a incursão em um tema que, apesar de não inédito, aparentemente tem sido pouco explorado pela produção científica da área da educação. Embora não consideremos ser significativa a representatividade que a amostra e a instituição eleitas em nossa investigação têm com relação à educação em geral, esta condição não retira a relevância que ela tem diante da necessidade de problematizar, com as devidas refutações, a questão do assédio moral nas práticas de gestão escolar, prática esta que fere não apenas os postulados atrelados à gestão democrática de ensino mas, também, a própria moral que, para qualquer relação interpessoal desejável, se impõe como condição. Sobretudo em uma instituição cuja justificativa da própria existência se dá, justamente, pela responsabilidade que tem no que se refere à formação humana, cuja essência, obrigatoriamente, deve erigir sobre os valores morais para que se produza a "boa educação". Nesse sentido, atitudes empreendidas axiologicamente a partir da lógica da intolerância, humilhação, menosprezo e demais formas de maltrato devem, sem dúvida, ser passíveis de reprovação em qualquer instituição educativa, sejam elas 
restritas à relação estabelecida entre gestores e professores ou expandidas para outras instâncias de convivência. Finalmente, sendo a escola um local onde a convivência é fato dado à sua natureza, outorga-se a ela zelar pelo bom convívio de todos os personagens, sejam eles gestores, professores, alunos ou funcionários. No caso de nossa investigação, ao verificar que a maioria das professoras pesquisadas manifesta como resposta às agressões sofridas sentimentos como angústia, desmotivação ou desânimo, dentre outros, comprovamos os riscos que as situações apresentam à sua sanidade psíquica. No entanto, considerando os limites metodológicos sob os quais desenvolvemos esta pesquisa, não é possível mensurar com mais precisão o quanto realmente estes riscos podem afetá-las. Para isso, seria necessário o estabelecimento de um estudo longitudinal, a fim de que os efeitos do assédio moral possam ser melhor depurados, a partir de uma perspectiva a "longo prazo".

Outra limitação que merece ser destacada se deve ao nosso próprio instrumento de investigação, cujas perguntas fechadas nos permitem, apenas, captar fotografias de uma realidade certamente mais complexa. Para imergir nas nuances subjacentes aos fatos representados e aos sentimentos mais profundos deles decorrentes, teríamos que recorrer ao método clínico, utilizado por autores como, por exemplo, Jean Piaget (1932), Lawrence Kohlberg (1992) e Carol Gilligan (1982). No entanto, além da demanda maior por tempo, teríamos que optar por entrevistas de caráter aberto, situações estas praticamente impraticáveis diante das condições para a realização de nosso estudo, no qual a própria coleta de dados não se deu sem resistência por parte da administração escolar.

Por fim, apesar de assinaladas tais limitações, as quais reconhecemos de antemão, assumindo-as como causa do caráter não conclusivo de nosso estudo, estamos certos de que, a partir dele, é possível a abertura para outros de maior dimensão, a fim de que a prática de assédio moral por parte dos gestores escolares possa ter sua imoralidade embasada e comprovada pela produção científica da educação e, com isso, sejam consolidados os argumentos sobre os quais podemos refutar, sem hesitar, o mau uso do poder por parte de quem não pode prescindir de seu bom uso. Para o bem da educação...

Recebido em: 19/04/2018, reapresentado em: 30/08/2018 e aprovado em: 12/09/2018

\section{Notas}

1 No caso da unidade educacional pesquisada, devido à ausência de um profissional responsável pela coordenação pedagógica ou pelo cargo de vice direção - ausências estas que, nas instituições públicas municipais responsáveis pela educação infantil de Ribeirão Preto/SP, são comuns - a diretora da escola é quem exclusivamente responde pela equipe de gestão. 
2 Constituição da República Federativa do Brasil, art. 206, de 05 de outubro de 1988.

3 Lei de Diretrizes e Bases da Educação Nacional (LDB), inciso VIII do art. 3º, de 20 de dezembro de 1996.

\section{Referências}

ARENDT, Hannah. A vida do espírito: o pensar, o querer, o julgar. Trad. de César Antônio Abranches. 4 ed. Rio de Janeiro: Relume Domará, 2000.

Entre o passado e o futuro. Tradução: Mauro W. Barbosa. 5. Ed. São Paulo: Perspectiva, 2009.

BRASIL. Constituição da República Federativa do Brasil. Brasília: Senado Federal: Centro Gráfico, 1988. 292 p.

Lei 9394/96 - Lei de Diretrizes e Bases da Educação Nacional. Disponível em < www.planalto. gov.br >. Acesso em: 08 de abril de 2018

COSTA, Isabelle Cristinne Pinto et. al. Produção científica acerca de assédio moral em dissertações e teses no cenário brasileiro. Revista da Escola de Enfermagem da USP, São Pulo: USP, v. 49, n. 2, p. 267-276, 2015.

DOURADO, Luiz Fernandez. Progestão: como promover, articular e envolver a ação das pessoas no processo de gestão escolar? Brasília: CONSED, 2001.

GILLIGAN. Carol. Uma voz diferente. Rio de Janeiro: Editora Rosa dos Tempos, 1982.

HIRIGOYEN, Marie-France. Assédio moral: a violência perversa no cotidiano. $5^{\mathrm{a}}$ ed. Rio de Janeiro: Bertrand Brasil, 2002.

JEONG, Deborah Ju Yong; KURCGANT, Paulina. Factors of work dissatisfaction according to the perception of nurses of a university hospital. Rev. Gaúcha Enferm, Porto Alegre: UFRGS, v. 31, n. 4, p. 655-61, 2010.

KOHLBERG, Lawrence. Estádios morales y moralización. El enfoque cognitivo-evolutivo. In: TURIEL, Eliot; ENESCO, Ileana; LINAZA, Josetxu. (compilación). El mundo social en la mente infantil. Madrid: Alianza Editorial, 1989.

. Psicologia del desarrollo moral. Bilbau: Biblioteca de Psicologia/ Desclée de Brouwer, 1992.

MOSCOVICI, Serge. Representações sociais: investigações em psicologia social. Rio de Janeiro, Vozes, 2003.

OLIVEIRA, Euler Sinoir. Assédio Moral: Sujeitos, Danos à Saúde e Legislação. Assédio Moral e Assédio Sexual, Rev. Eletrônica: TRTPR, v. 23, n.184, p. 128-147, 2013.

ORGANIZATION INTERNACIONAL DEL TRABAJO. Um informe de la OIT. Disponível em: http:// www.ilo.org/public/spanish/bureau/inf/pr/2000/37. htm. Acesso em: 10 mai. 2003.

PARO, Vitor Henrique. Gestão democrática da escola pública. São Paulo: Cortez, 2017.

PIAGET, Jean. O juízo moral na Criança. São Paulo: Summus, 1932/1994.

. Las relaciones entre la inteligencia y la afectividad en el desarrollo mental del ninõ. In: DELAHANTY, G. PERRËS (Comp). Piaget y el psicoanálisis. México: Universidade Autonoma Metropolitana, 1952/1994, pp. 181-290. 